NATIONAL LABORATORY

\title{
Graphite Sublimation Tests for the Muon Collider/Neutrino Factory Target Development Program
}

February 2002

J. R. Haines and C. C. Tsai 


\section{DOCUMENT AVAILABILITY}

Reports produced after January 1,1996, are generally available free via the U.S. Department of Energy (DOE) Information Bridge:

Web site: http://nww.osti.gov/bridge

Reports produced before January 1,1996 , may be purchased by members of the public from the following source:

National Technical Information Service

5285 Port Royal Road

Springfield, VA 22161

Telephone: 703-605-6000 (I-800-553-6847)

TDD: 703-487-4639

Fax: 703-605-6900

E-mail: infoQntis.fedworld.gov

Web site: http://www.ntis.gov/support/ordernowabout.htm

Reports are available to DOE employees, DOE contractors, Energy Technology Data Exchange (ETDE) representatives, and International Nuclear Information System (INIS) representatives from the following source:

Office of Scientific and Technical Information

P.O. Box 62

Oak Ridge, TN 37831

Telephone: $865-576-8401$

Fax: 865-576-5728

E-mail: reports@adonis.osti.gov

Web site: http://www.osti.gov/contact.html

This report was prepared as an account of work sponsored by an agency of the United States Government. Neither the United States government nor any agency thereof, nor any of their employees, makes any warranty, express or implied, or assumes any legal liability or responsibility for the accuracy, completeness, or usefulness of any information, apparatus, product, or process disclosed, or represents that its use would not infringe privately owned rights. Reference herein to any specific commercial product, process, or service by trade name, trademark, manufacturer, or otherwise, does not necessarily constitute or imply its endorsement, recommendation, or favoring by the United States Government or any agency thereof. The views and opinions of authors expressed herein do not necessarily state or reflect those of the United States Government or any agency thereof. 


\title{
GRAPHITE SUBLIMATION TESTS \\ FOR THE MUON COLLIDER/NEUTRINO FACTORY \\ TARGET DEVELOPMENT PROGRAM
}

\author{
J. R. Haines \\ C. C. Tsai
}

Date Published: February 2002

Prepared for the

U.S. Department of Energy

Office of Science

UT-BATTELLE，LLC

managing

Spallation Neutron Source activities at

Argonne National Laboratory

Thomas Jefferson National Accelerator Facility

Los Alamos National Laboratory
Brookhaven National Laboratory

Lawrence Berkeley National Laboratory

Oak Ridge National Laboratory

under contract DE-AC05-00OR22725

for the

U.S. DEPARTMENT OF ENERGY 


\section{PAGE INTENTIONALLY LEFT BLANK}




\section{CONTENTS}

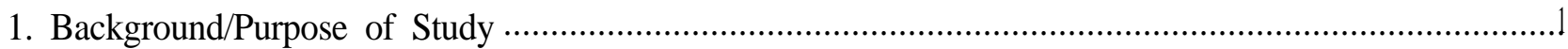

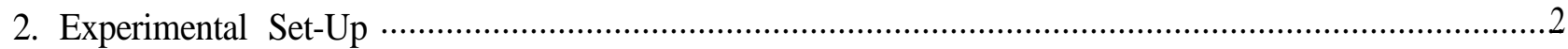

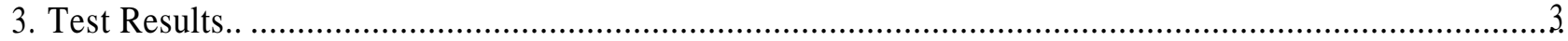

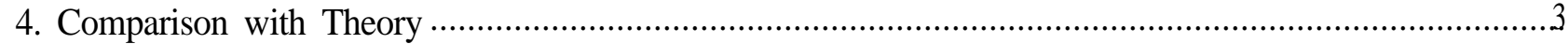

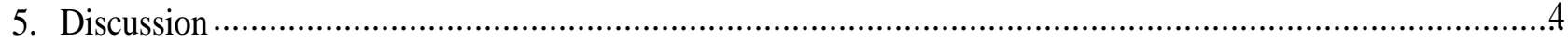

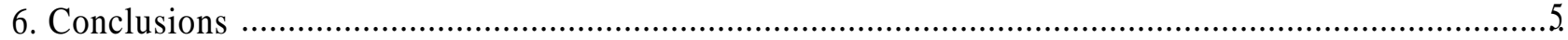

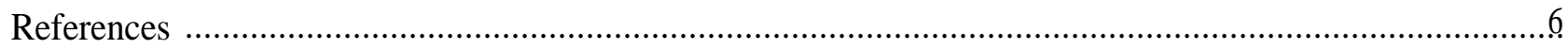




\section{LIST OF FIGURES}

Figure $\quad$ Page

1. Graphite target design concept for a neutrino factory facility.................................................. ${ }^{7}$

2. Graphite vapor pressure and erosion rate into a perfect vacuum ................................................. 8

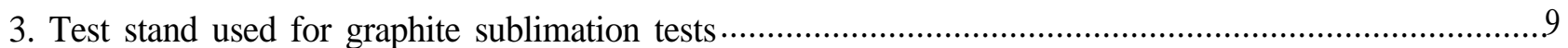

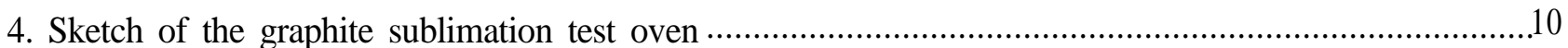

5. Sketch of a graphite foil used in sublimation tests …...........................................................11

6. Comparison of measured weight losses to theoretical predictions …...............................................12

7. Graphite vapor pressure and erosion rate into a perfect vacuum …..............................................13

8. Surface temperature of radiatively cooled graphite target as a function of volumetric heating rate.. $\cdots 14$

9. Erosion rate versus heat deposition rate for a radiatively cooled graphite rod target.. ........................15

10. Sublimation erosion lifetime limits for a graphite neutrino factory target. …................................16 


\section{LIST OF TABLES}

Table

Page

1. Measured weight losses for sublimation tests in high vacum ............................................ 3

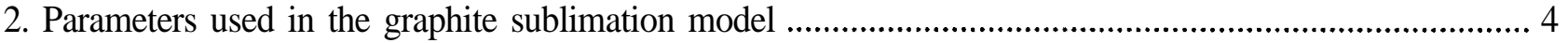


PAGE INTENTIONALLY LEFT BLANK 


\title{
Graphite Sublimation Tests \\ for the Muon Collider/Neutrino Factory \\ Target Development Program
}

\author{
J. R. Haines and C. C. Tsai
}

\section{Background/Purpose of Study}

A passively cooled graphite target was proposed for a 1.5 MW neutrino production research facility because of its simplicity and favorable performance as a target material for neutrino production (Ref. 1). The conceptual design for the target in the Reference 1 study was a graphite rod $15 \mathrm{~mm}$ in diameter by $800 \mathrm{~mm}$ long. Figure 1 shows the graphite target rod supported by graphite spokes, which are mounted to a water-cooled stainless steel support tube. The target is radiatively cooled to the water-cooled surface of the support tube.

Based on nuclear analysis results (Ref. 2), the time-averaged power deposition in the target is $35 \mathrm{~kW}$. If this power is deposited uniformly along the axial length of the target, the volumetric power deposition in the target is about $250 \mathrm{MW} / \mathrm{m}^{3}$. The target surface temperature required to radiate the deposited power to a water-cooled tube is estimated to be about 1850 " $\mathrm{C}$, and the temperature at the center of the target is about $75^{\circ} \mathrm{C}$ hotter.

The sublimation erosion rate (e), estimated assuming that the graphite is submersed in a perfect vacuum environment, can be derived from kinetic theory and is given by:

$$
e=p_{s a t}\left(\frac{m}{2 \pi k T}\right)^{1 / 2}
$$

where $\mathrm{p}_{\text {sat }}$ is the saturation pressure, $\mathrm{m}$ is the molecular weight, $\mathrm{k}$ is the Boltzmann constant, and $\mathrm{T}$ is the surface temperature. The saturation pressure given in Ref. 3 can be approximated by:

$$
p_{\text {sat }}=\exp \left(-\frac{A}{T}+B\right)
$$

where $\mathrm{A}=9.47 \times 10^{3}, \mathrm{~B}=24.2$, and the units of $\mathrm{p}_{\text {sat }}$ and $\mathrm{T}$ are atmospheres and $\mathrm{K}$, respectively. Using these equations, the saturation pressure and sublimation erosion rate are plotted in Fig. 2 as a function of temperature. The surface recession rate shown with units of $\mathrm{mm} / \mathrm{s}$ in Fig. 2 assumes one-sided erosion.

At the average power deposition value of $250 \mathrm{MW} / \mathrm{m}^{3}$, the surface temperature is $1850{ }^{\circ} \mathrm{C}$ resulting in a sublimation erosion rate of only $2.2 \mu \mathrm{m} /$ day. However, if the actual power deposition were peaked by a factor of two in the axial direction, then the surface temperature would be $2260{ }^{\circ} \mathrm{C}$ and the surface recession rate would be $2.8 \mathrm{~mm} /$ day, which is clearly unacceptable.

To establish the viability of a graphite target at the reference power levels and perhaps extend the power handling performance of radiatively cooled graphite targets, a helium cover gas at nominally one atmosphere pressure was proposed as a means to greatly reduce the net erosion rate. The mean free path for a graphite atom in a helium environment at a pressure of one atmosphere is less than $0.1 \mu \mathrm{m}$, which means that graphite that is sublimated from the target surface will travel on average less than $0.1 \mu \mathrm{m}$ before it interacts with the helium. Given this small mean-free-path, it can be expected that a large fraction of the graphite that is sublimated will find its way back to the graphite surface and re-condense on the target, thereby greatly reducing the net erosion rate.

The primary purposes for performing the tests described in this report are to (1) verify that we can reproduce the sublimation erosion rate expected for high vacuum conditions and (2) establish the reduction in net sublimation of graphite as a function of the gas $(\mathrm{He})$ pressure in a chamber that roughly 
simulates the stainless steel support tube discussed above. Thus far, the first objective has been accomplished, but more work is required to accomplish the second.

The experimental apparatus is described in Section 2 of this report and results obtained thus far are presented in Section 3 of this report.

\section{Experimental Set-Up}

To conduct graphite sublimation experiments in the range of interest in this study, an oven capable of heating a graphite foil to temperatures of $-2500 \mathrm{~K}$ is needed. The walls of the oven need to be sufficiently cool to condense carbon vapor evaporated from the foil. In addition, the test chamber should be capable of conducting tests at various pressures from vacuum to 1 bar of helium. To fulfill these goals, we selected a concept that uses the graphite foil itself as an electrical heater. The temperature of the graphite foil is changed by controlling the electrical current. The weight loss of the graphite foil is used to estimate the evaporation rate of the graphite foil. To conduct such an experiment, we modified an existing test stand in the Plasma Source Facility in the Fusion Energy Division at Oak Ridge National Laboratory.

The test stand has been modified and prepared as shown in Fig. 3. It consists of a test chamber, a vacuum and gas feed system, a temperature measurement system, and an oven. The control consoles, associated power supplies, and electronic instrument and data acquisition system are not shown in this figure. In the test chamber, water-cooled heat shields are used to condense carbon vapor and keep the walls of the test chamber near room temperature. Consequently, the graphite foil sublimation tests can be conducted at temperatures up to $2550 \mathrm{~K}$.

The vacuum and gas feed system provide a controllable environment for these graphite sublimation tests. The mechanical roughing pump and the turbo-molecular pump can evacuate the test chamber to a base pressure below $10^{-6}$ torr. Together with the vacuum system, the gas feed system can be used to feed pure helium gas into the test chamber at pressures controllable from vacuum up to 1 bar.

The temperature measurement system consists of a two-color pyrometer and a quartz window. Viewing through the quartz window, the ratio of radiation signals of two adjacent wavelengths from the heated graphite foil is measured and used to indicate the surface temperature of the graphite foil. This two-color pyrometer (IRCON Modline R) can measure temperatures from $1373 \mathrm{~K}$ to $2773 \mathrm{~K}$.

Figure 4 shows a sketch of the test oven. The graphite foil is mounted and fastened to graphite posts by graphite screws. The graphite posts are fastened to water-cooled copper feedthroughs that are brazed on a copper flange. A water-cooled copper liner is used to enclose the graphite foil and associated components. During these tests, the output terminals of a dc power supply are connected to the copper feedthroughs. The voltage measured between the feedthroughs is the heating voltage $\mathrm{V}_{\mathrm{h}}$. The current flowing through the graphite foil is the heating current $I_{h}$. By controlling the heating voltage, the heating current is adjusted to heat the foil to the test temperature. The dc power supply, which is rated at $15 \mathrm{~V}$ and $500 \mathrm{~A}$, is sufficient for heating the graphite foil to $2550 \mathrm{~K}$ at pressures from vacuum to 1 bar helium.

A sketch of the 38-mm long, $19 \mathrm{~mm}$ wide, and 1-mm thick graphite foil is shown in Fig. 5. An electronic balance with 5 significant digits is used to measure the mass of the graphite foil. Usually the graphite foil is baked in an oven at $700 \mathrm{~K}$ for a few hours to allow for adequate outgassing before its mass is measured. Following the sublimation test, the mass of the graphite foil is measured again. The mass loss and test duration are recorded to estimate the evaporation rate of the foil.

In addition to measuring graphite foil temperature $(T$,$) on separate digital and analog meters, we also$ measure the wall temperature of the test chamber and copper liner by using a thermocouple, the heating voltage $\left(V_{h}\right)$ across the copper feedthrough and the heating current $\left(\mathrm{I}_{h}\right)$ passing through the graphite foil. The analog electrical signals for $\mathrm{T},, \mathrm{V}_{\mathrm{h}}$, and $\mathrm{I}_{\mathrm{h}}$ are recorded and logged on a digital scope. With these measurements we are able to conduct post-test analysis of the multi-hour long tests. 


\section{Test Results}

The weight loss measurement data for temperatures between $2393 \mathrm{~K}$ and $2300 \mathrm{~K}$ are listed in Table 1. Temperatures above this range were not achieved because manual control of the temperature becomes problematic; i.e. an automatic control system is required to maintain constant temperature. It is worth noting that even over this relatively small range of temperatures $(\sim 100 \mathrm{~K}$ difference), the erosion rate varies by more than an order of magnitude. The steady state values for relevant heating parameters such as $\mathbf{V}_{\mathrm{h}}, \mathbf{I}_{\mathrm{h}}$, and $\mathbf{R}_{\mathrm{h}}$ are also listed in Table 1 .

A comparison of this data with theoretical predictions and the implications of these results on power limitations for a neutrino factory facility that uses a radiatively cooled graphite target in a high vacuum environment are discussed in subsequent sections.

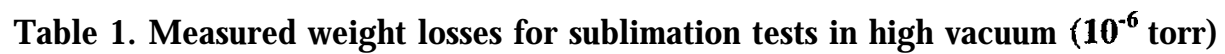

\begin{tabular}{ccccc}
\hline $\begin{array}{c}\text { Graphite Surface } \\
\text { Temperature (K) }\end{array}$ & $\begin{array}{c}\mathrm{I}_{\mathrm{h}} \\
(\mathrm{A})\end{array}$ & $\begin{array}{c}\mathrm{V}_{\mathrm{h}} \\
(\mathrm{V})\end{array}$ & $\begin{array}{c}\mathrm{R}_{\mathrm{h}} \\
(\mathrm{milli}-\mathrm{ohm})\end{array}$ & $\begin{array}{c}\text { Weight Loss Rate } \\
(\mathrm{mg} / \mathrm{h})\end{array}$ \\
\hline 2393 & 330 & 11.9 & 36.1 & 0.58 \\
2403 & 331 & 11.9 & 36.0 & 0.67 \\
2413 & 333 & 12.0 & 36.0 & 1.01 \\
2413 & 332 & 12.1 & 36.3 & 1.32 \\
2407 & 332 & 12.0 & 36.2 & 1.45 \\
2480 & 360 & 12.5 & 34.6 & 6.75 \\
2500 & 348 & 12.8 & 36.8 & 9.37 \\
\hline
\end{tabular}

\section{Comparison with Theory}

To make a comparison with theory and thereby validate the experimental apparatus and measurements, a computer model was developed to predict the mass loss of a graphite sample. The computer model was used to compute the temperature distribution on the sample and then numerically integrate the erosion rate over the surface of the sample to obtain the total mass loss. The equation for free vaporization shown above was used to obtain the vaporization rate for each finite volume in the numerical model. The model included:

- One dimensional heat conduction axially along the support rods and along the length of the sample

- Radiation to the surroundings

- Phase change energy

- Joule heating of the sample and its support rods

- Contact resistance at the sample/support rod interface

A list of the model parameters including assumed material properties is shown, in Table 2. Since there is some uncertainty in the material properties, especially at the elevated temperatures experienced in these 
tests, sensitivity studies were conducted. These studies showed that within their expected range, material property uncertainties had no significant effect on the results. Another uncertainty in the model parameters is in the thermal contact resistance at the support rod/graphite sample interface. Results were also shown to be relatively insensitive to this parameter over the range of uncertainty.

There is some uncertainty in the saturation pressure and thus evaporation rate for graphite. This is primarily due to the fact that both monatomic and polyatomic species of carbon result from the vaporization of graphite, and the mix of species varies with type of graphite and temperature, The resulting variation in theoretical sublimation erosion rate is shown in Fig. 6 for saturation pressure curves found in Refs. 3 and 4. The erosion data for high vacuum conditions presented in the previous section are repeated in Fig. 6 for comparison with the theoretical results.

The measured data appear to agree well with the predictions using the saturation pressure given in Ref. $4(\mathrm{~A}=87,230$ and $\mathrm{B}=18.3)$. The fact that the data fall near or even slightly below the low end of the theoretical predictions could be due to a small amount of re-condensation that will occur in any real apparatus.

The data taken so far validate the apparatus under high vacuum conditions. Attempts to conduct tests with one atmosphere of helium in the test chamber have been unsuccessful. It appears that arcing from the support rod to the sample, i.e., across the relatively high resistance at the support rod and sample contact region, cause damage to the sample until it breaks into pieces. Further attempts with more arc resistant shapes and better interface contact will be attempted in the future. Meanwhile, the implications of a lower sublimation rate, such as that consistent with the Ref. 4 data, on target power handling limits has been evaluated, and is discussed in the following section of this report.

Table 2. Parameters used in the graphite sublimation model

\begin{tabular}{lc}
\hline \multicolumn{1}{c}{ Parameter } & Value \\
\hline & \\
Properties of graphite test specimen: & 1730 \\
Density $\left(\mathrm{kg} / \mathrm{m}^{3}\right)$ & 30 \\
Thermal conductivity $(\mathrm{W} / \mathrm{m}-\mathrm{K})$ & 10 \\
Electrical resistivity (micro-ohm-m) & 0.8 \\
Emissivity & .005 \\
& \\
Thermal contact resistance between & 500 \\
support rod and specimen $\left(\mathrm{K}-\mathrm{m}^{2} / \mathrm{W}\right)$ & \\
Temperature of surroundings $(\mathrm{K})$ & \\
\hline
\end{tabular}

\section{Discussion}

The data shown in Fig. 2 are repeated in Fig. 7 along with a new erosion rate for the Ref. 4 data. The erosion rate calculated using the Ref. 4 data for saturation pressure is more than an order of magnitude lower than those calculated using the Ref. 3 data.

Assuming radiation cooling, the operating temperature of the target surface is shown in Fig. 8 as a function of the volumetric heating rate. Combining the information shown in Figs. 7 and 8, the erosion rate is shown in Fig. 9 as a function of the heat deposition rate. At the average heating rate for a $1.5 \mathrm{MW}$ facility $\left(250 \mathrm{MW} / \mathrm{m}^{3}\right)$, the erosion rate is acceptably small in either case. However, if the peak heating rate is assumed to be $50 \%$ higher than the average value, the erosion rate predicted using the Ref. 3 data is $0.2 \mathrm{~mm} /$ day, which means that the lifetime will be only a few days, whereas the erosion rate predicted using the Ref. 4 data is only $0.01 \mathrm{~mm} /$ day, which clearly yields an acceptable erosion lifetime. 
- $\quad$ For illustration purposes only, we make the following assumptions:

- The saturation pressure data from Ref. 4 are used to predict the sublimation erosion rate.

- The peak energy deposition in the target is a factor of two higher than the average value.

- The lifetime of a $7.5 \mathrm{~mm}$ radius target is defined to be the time at which the target radius is reduced by $1 \mathrm{~mm}$.

For this situation, the lifetime can be predicted as a function of the power level of the neutrino factory facility. Such a plot is shown in Fig. 10. A lifetime of one month is possible for a neutrino factory facility operating at about 1.2 MW. Presumably, we could extend the concept to higher powers using the helium environment to promote re-condensation.

\section{Conclusions}

Measurements of mass loss by sublimation validate the experimental apparatus and procedure under high vacuum conditions. Measured mass loss rates are close to or slightly less than predicted values. This is consistent with the fact that the theoretical predictions assume no re-condensation of evaporated material, whereas some re-condensation will occur. The measured sublimation erosion rate data appear to be consistent with saturation pressure data from a different source than used for initial target studies. Using this lower saturation pressure data significantly extends the power handling limits for a graphite target in a high vacuum environment. For example, if we assume that the peak heat deposition along the length of the graphite target is a factor of two higher than the average and that a 2 $\mathrm{mm}$ reduction in the target diameter defines the end-of-life, a lifetime of 1 month is achieved if the neutrino factory facility operates with a proton beam power of about 1.2 MW.

Attempts to make similar measurements with a one-atmosphere helium environment have been unsuccessful so far due to damage of the specimens that is attributed to arcing from the support rods to the specimens. Further efforts will be made to gather data in a helium environment with the expectation that there will be a significant reduction in erosion rate and increase in erosion lifetime. 


\section{References}

1. N. Holtkamp et al., "FNAL Feasibility Study on a Neutrino Source Based on a Muon Storage Ring," Fermi National Laboratory, Batavia, Illinois (April 2000).

2. N. V. Mokhov, “ $\pi / \mu$ Yield and Power Dissipation for Carbon and Mercury Targets in 20-Tesla Solenoid with Matching Section," Mucool Note MUC0061, Fermi National Laboratory, Batavia, Illinois (1999).

3. The Industrial Graphite Engineering Handbook, Union Carbide Corporation (1969).

4. Darken, L.S. and Gurry, R.W., Physical Chemistry of Metals, McGraw-Hill (1953). 


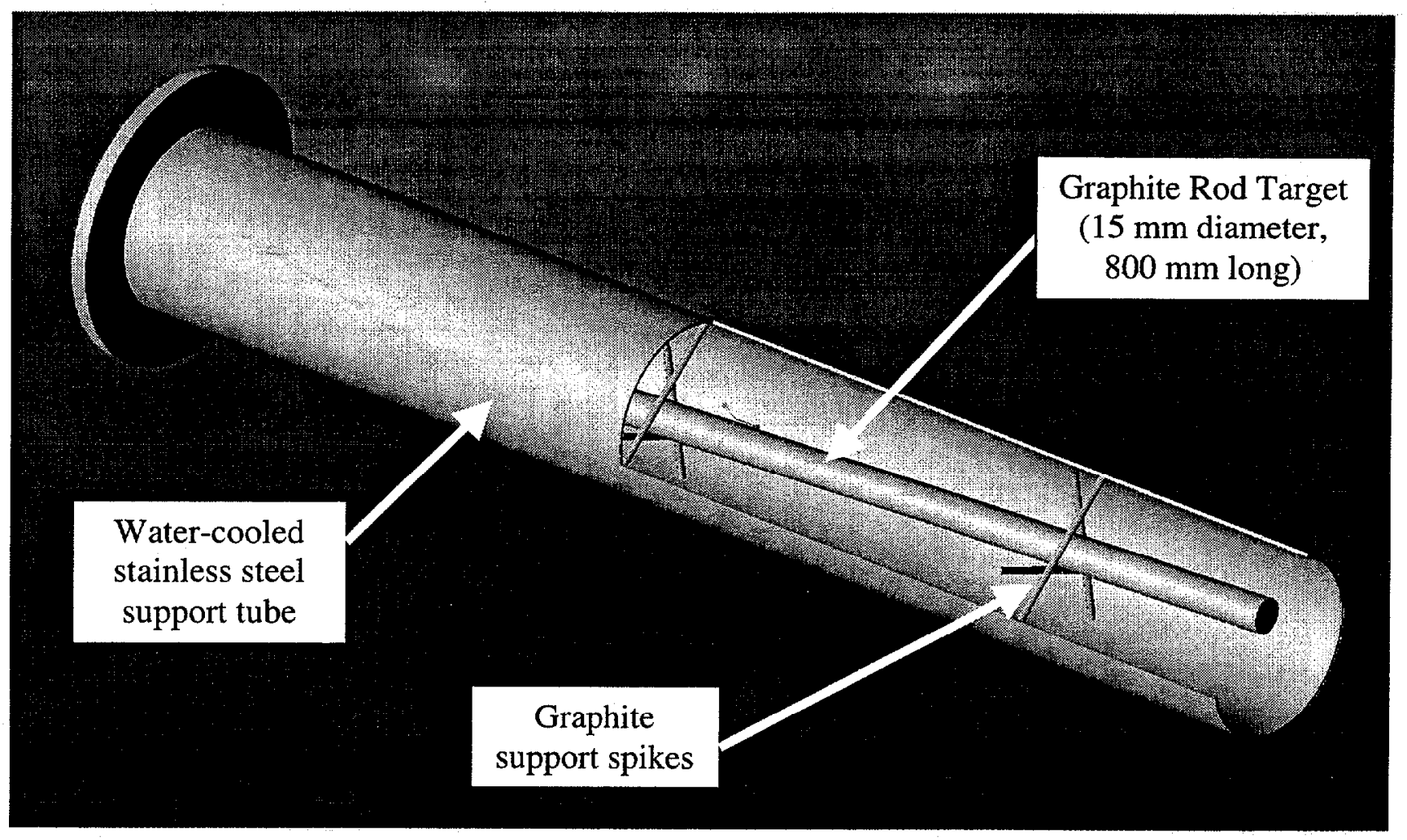

Fig. 1. Graphite target design concept for a neutrino factory facility. 


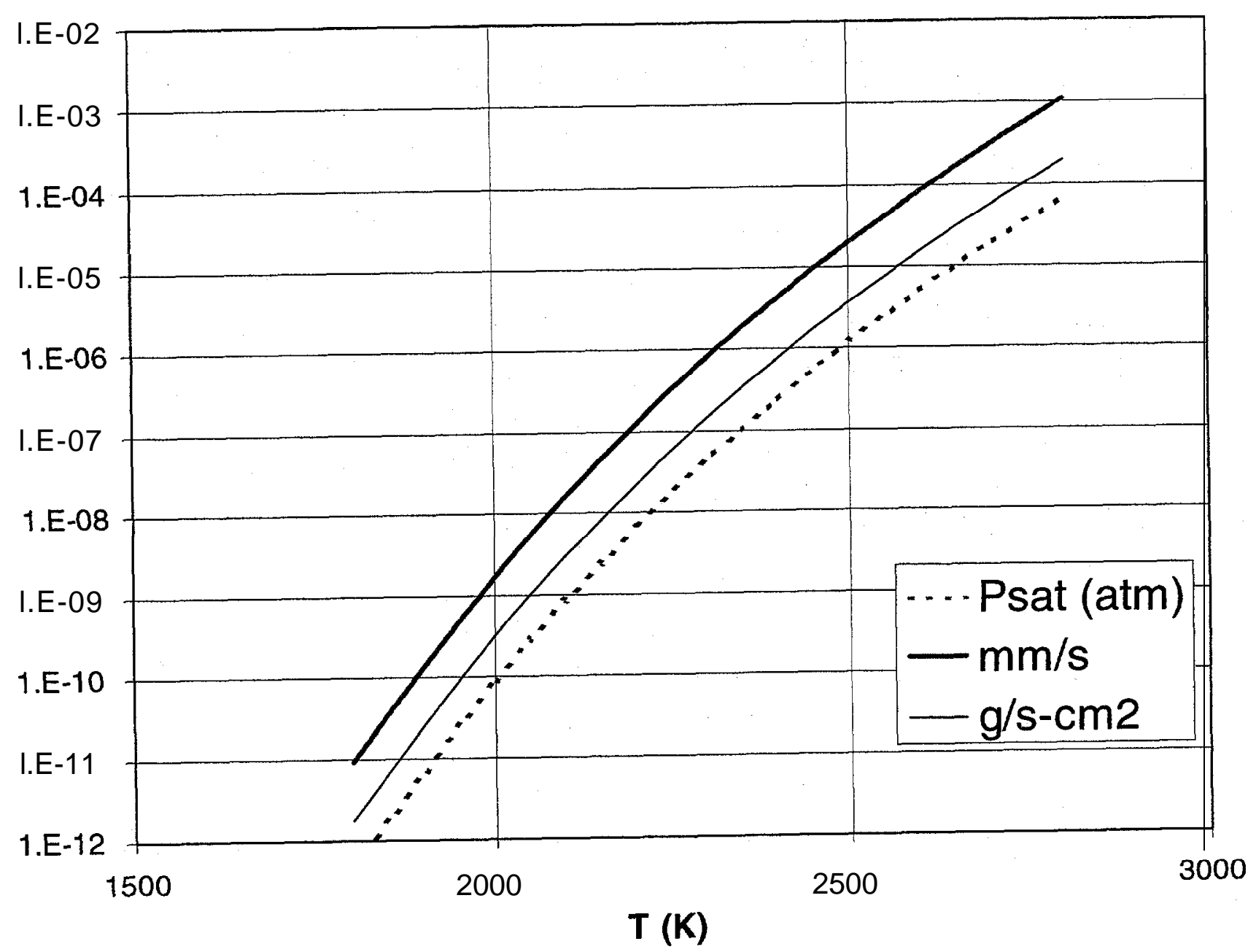

Fig. 2. Graphite vapor pressure and erosion rate into a perfect vacuum (using saturation pressure data from Ref. 3). 


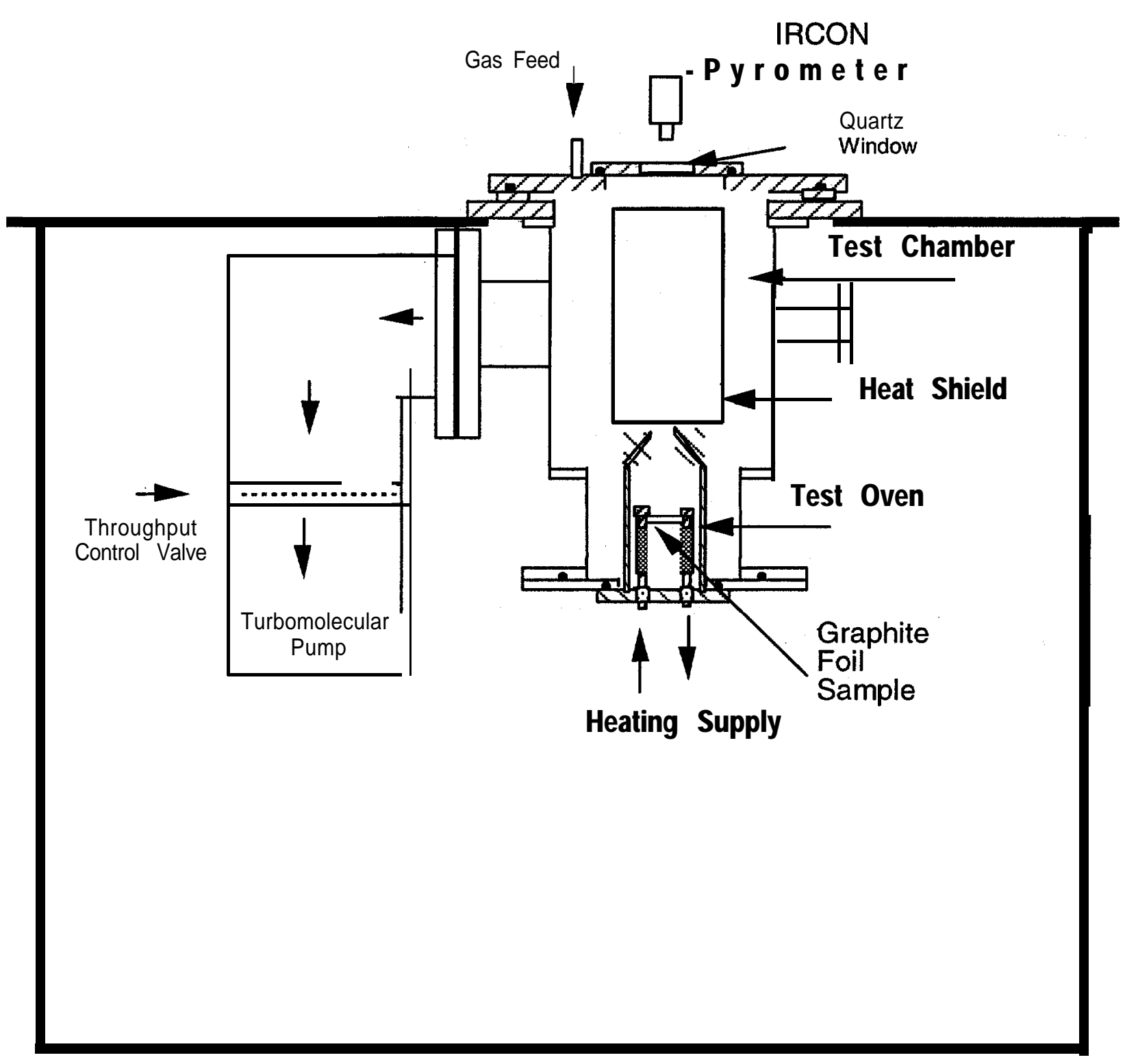

Fig. 3. Test stand used for graphite sublimation tests. 


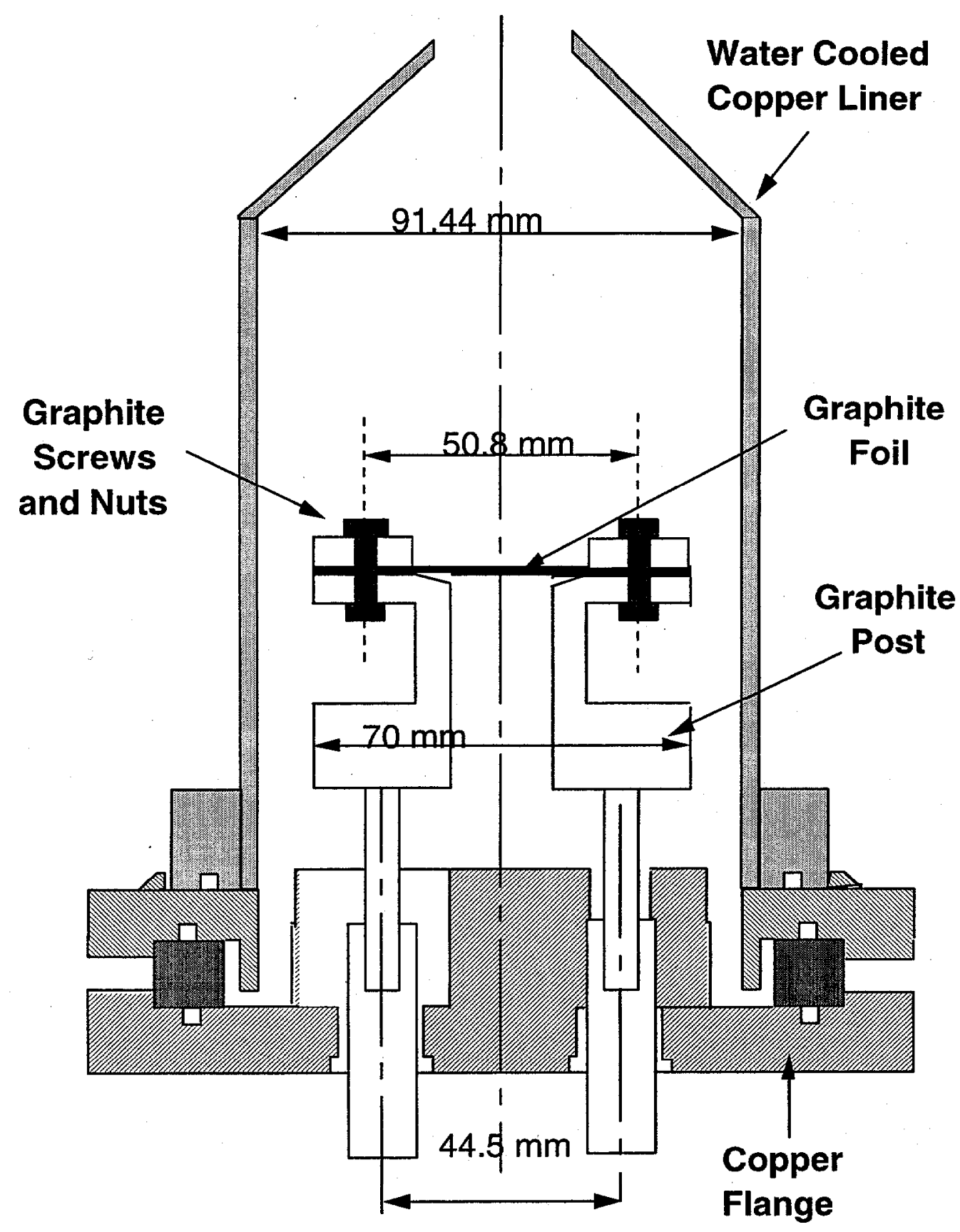

Fig. 4. Sketch of the graphite sublimation test oven. 

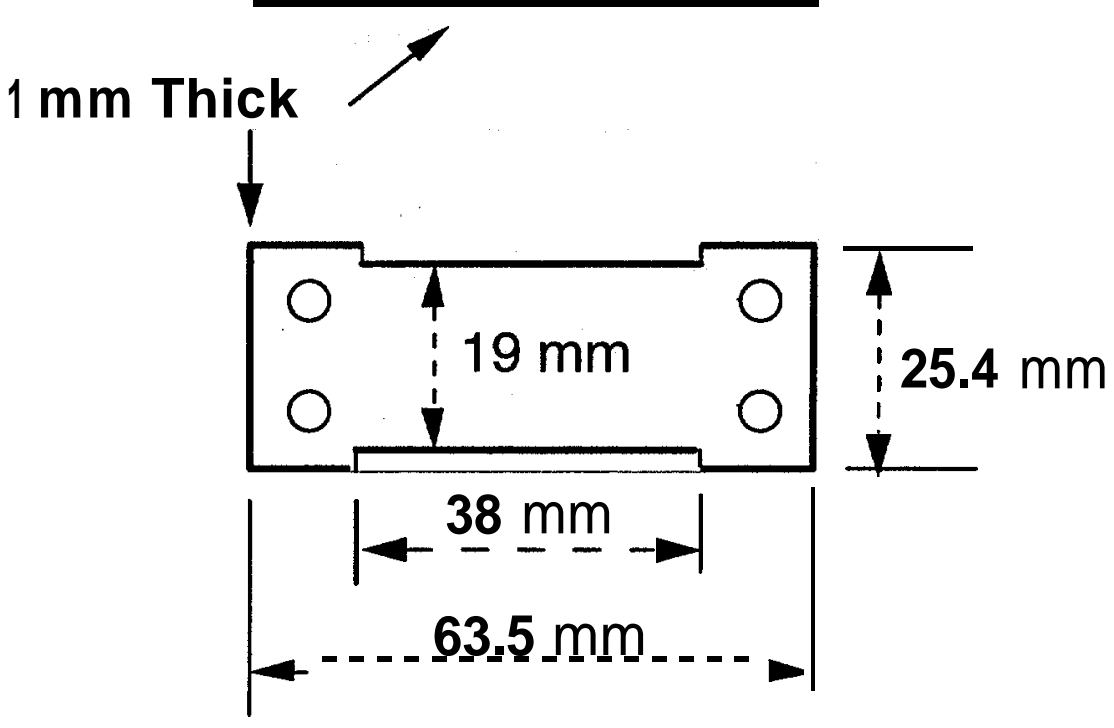

Fig. 5. Sketch of a graphite foil used in sublimation tests. 


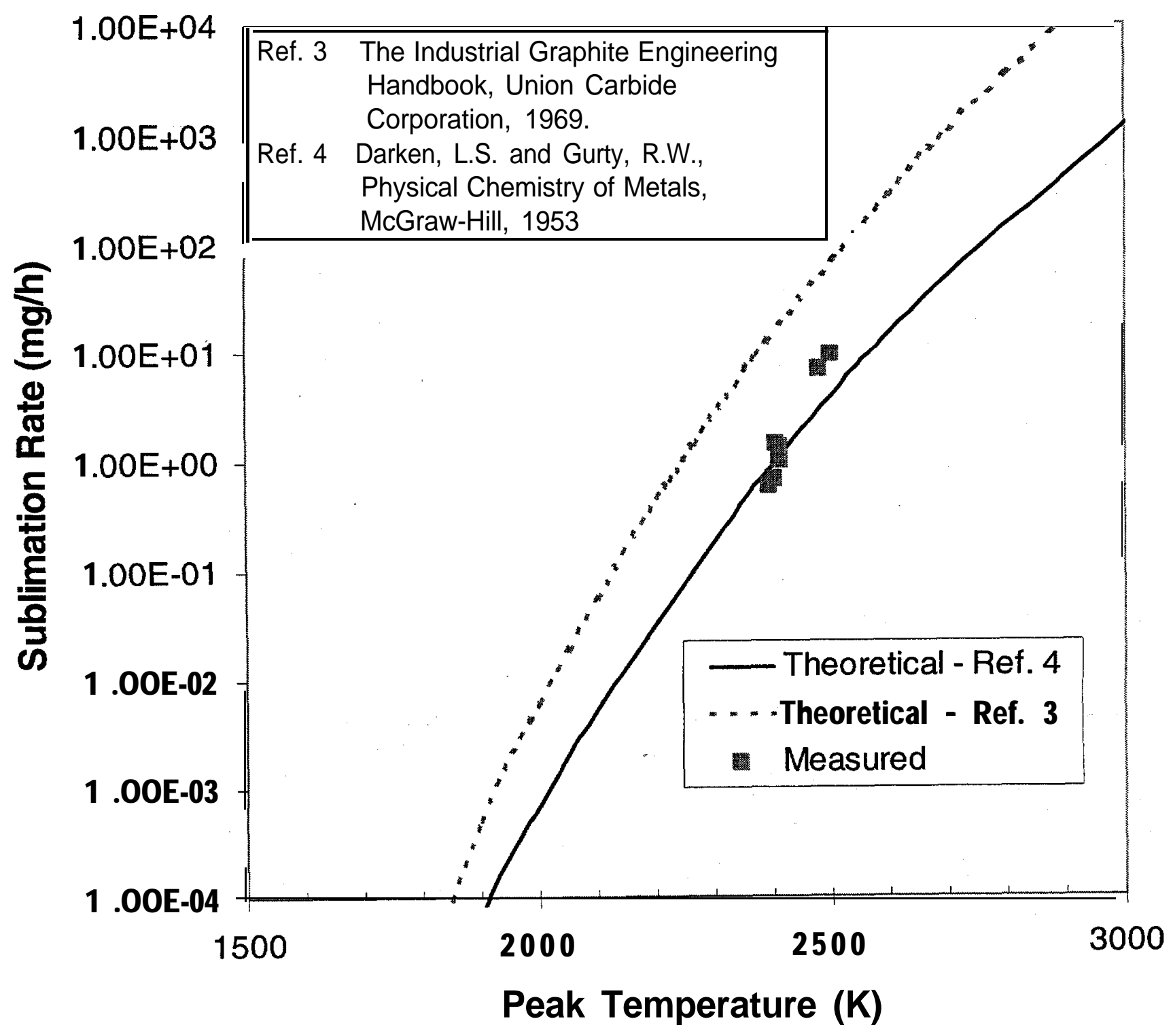

Fig. 6. Comparison of measured weight losses to theoretical predictions. 


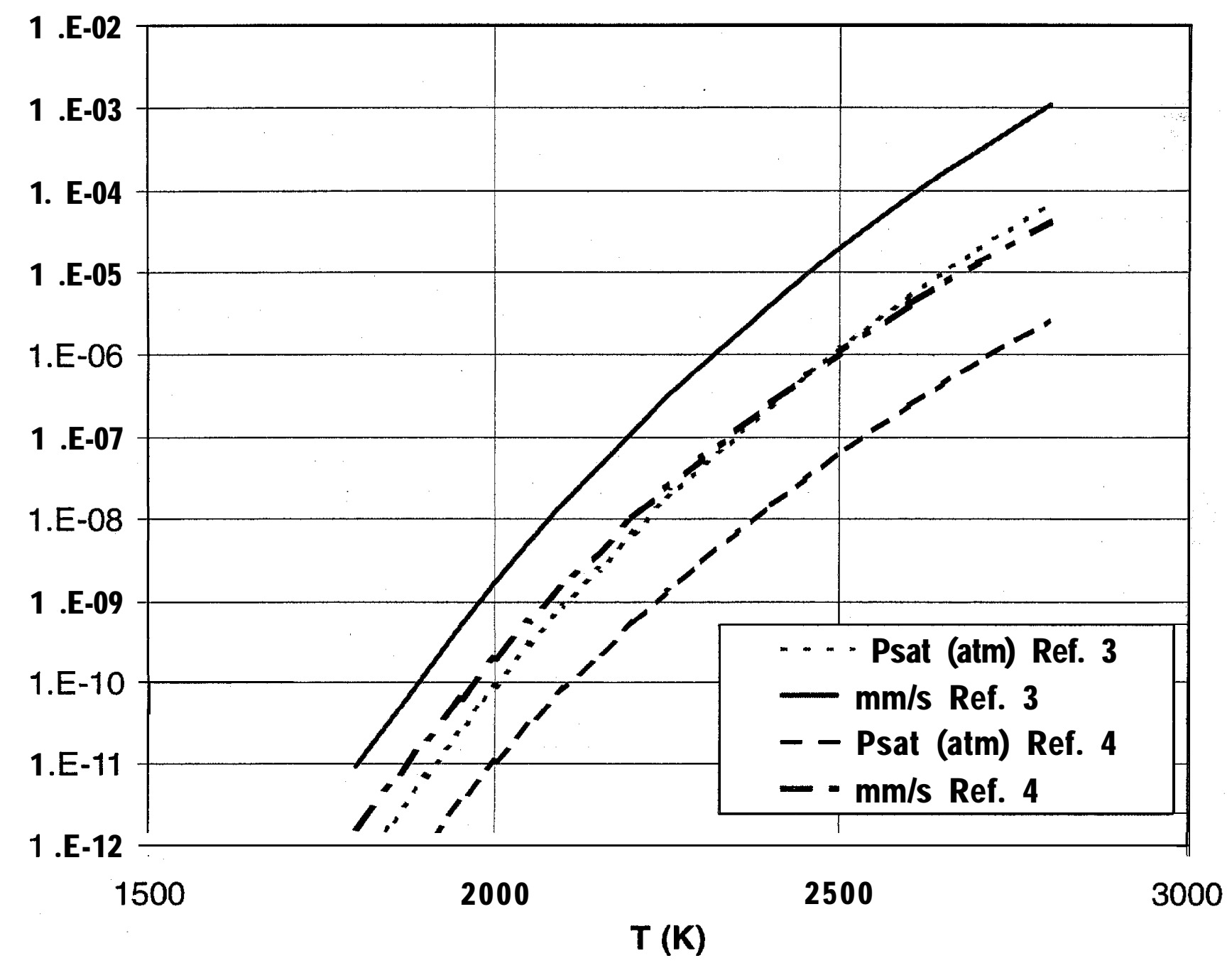

Fig. 7. Graphite vapor pressure and erosion rate into a perfect vacuum (using saturation pressure data from R efs. 3 and 4 ). 


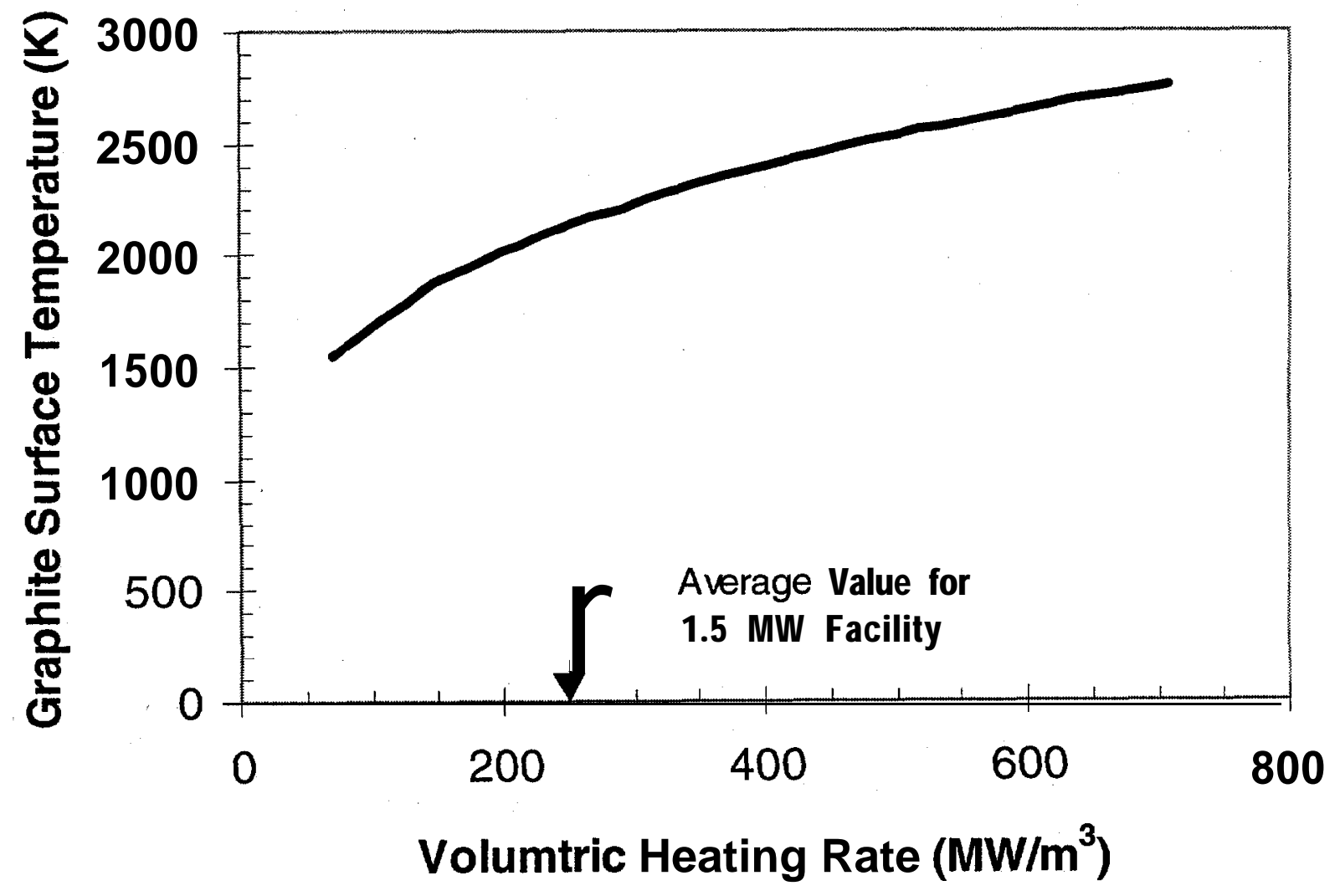

Fig. 8. Surface temperature of radiatively cooled graphite target as a function of volumetric heating rate. 


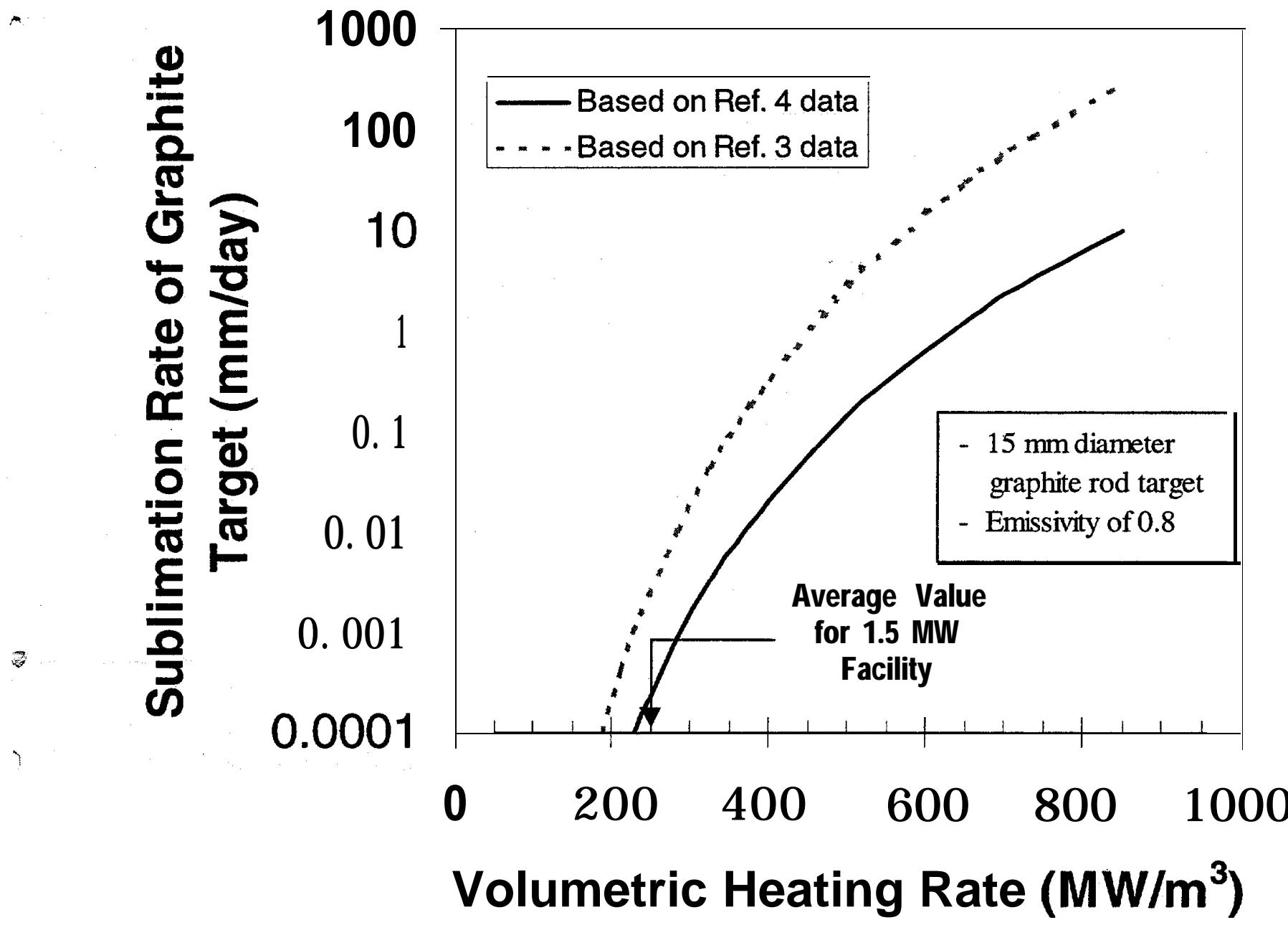

Fig. 9. Erosion rate versus heat deposition rate for a radiatively cooled graphite rod target. 


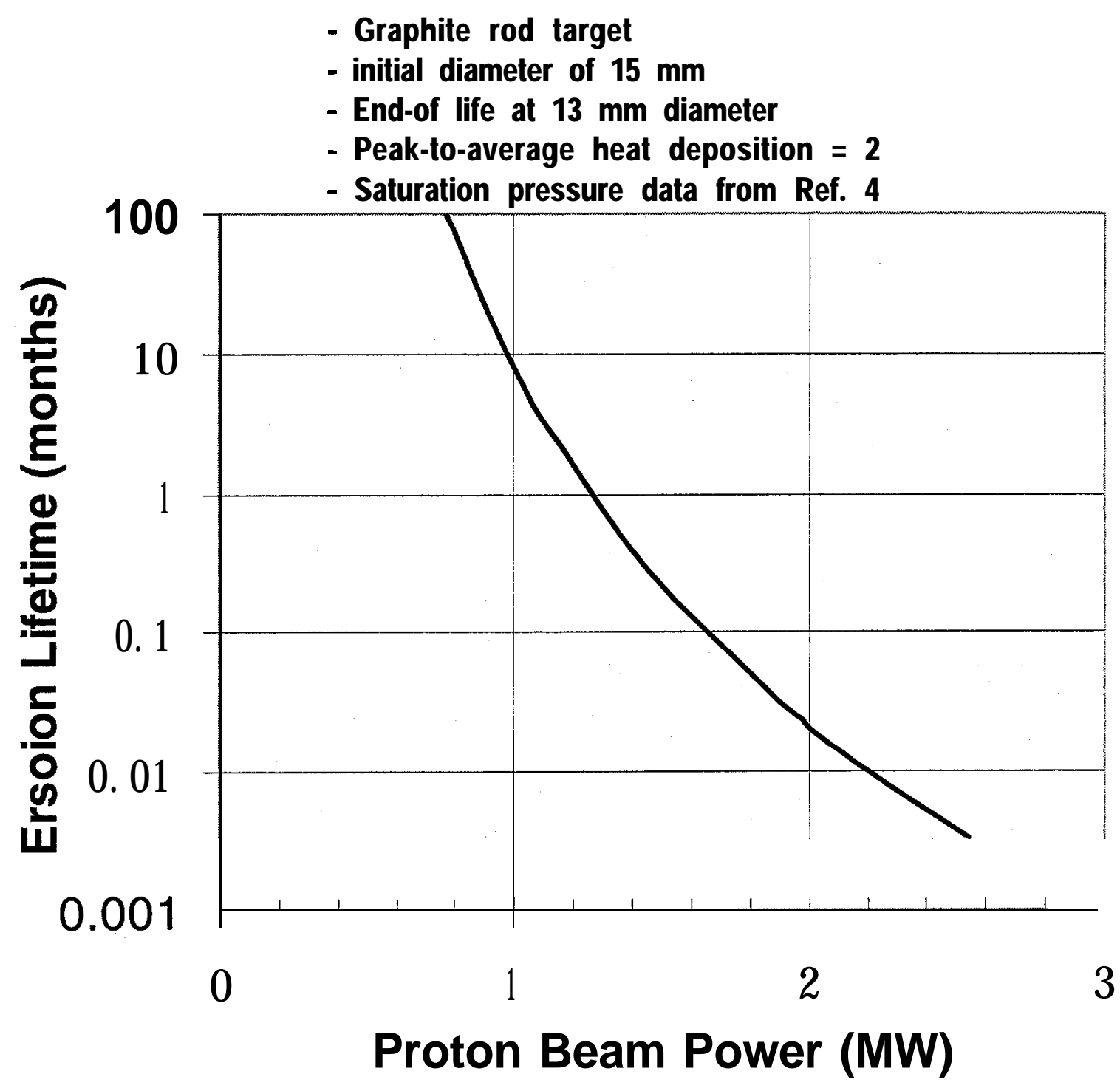

Fig. 10. Sublimation erosion lifetime limits for a graphite neutrino factory target. 


\section{INTERNAL DISTRIBUTION}

$\begin{aligned} \text { 1. } & \text { I. Anderson } \\ 2 . & \text { F. E. Bertrand } \\ 3 . & \text { T. A. Gabriel } \\ 4 . & \text { F. X. Gallmeier } \\ \text { 5-9. } & \text { J. R. Haines } \\ \text { 10. } & \text { N. R. Holtkamp } \\ \text { 11. } & \text { D. C. Lousteau } \\ \text { 12. } & \text { T. E. Mason } \\ \text { 13. } & \text { T. J. McManamy } \\ \text { 14. } & \text { G. E. Michaels }\end{aligned}$

\author{
15. S. L. Milora \\ 16. D. Rasmussen \\ 17. B. W. Riemer \\ 18. P. T. Spampinato \\ 19. C. N. Strawbridge \\ 20. C. C. Tsai \\ 21. M. W. Wendel \\ 22. ORNL Central Research Library \\ 23. Laboratory Records
}

\section{EXTERNAL DISTRIBUTION}

24. Sam Childress, Fermilab, P.O. Box 500, BD-NUMI, Mail Station 220, WH 12W, Batavia, IL 605100500.

25. David Finley, Fermilab, P.O. Box 500, TD-Administration, Mail Station 3 16, ICB 2W, Batavia, IL $60510-0500$.

26. Thomas Handler, University of Tennessee, Physics Department, 404 Nielsen Physics Bldg., Knoxville, TN 37996.

27. Harold Kirk, Brookhaven National Laboratory, P.O. Box 5000, Physics Department, Building 901A, Upton, NY 11973-5000.

28. Kirk McDonald, Princeton University, Physics Department, 309 Jadwin Hall, Princeton, NJ 08544.

29. Niolai Mokhov, Fermilab, P.O. Box 500, BD-DH-Beam Physics Department, Mail Station 220, WH 12E, Batavia, IL 6051 o-0500.

30. John R. O'Fallon, Director, High Energy Physics Division, 19901 Germantown Road, SC-22, Room G454, Germantown, MD 20874.

31. S. P. Rosen, Office of High Energy and Nuclear Physics, U.S. Department of Energy, 19901 Germantown Road, SC-20, Room H-410, Germantown, MD 20874.

32. Andrew Sessler, Lawrence Berkeley National Laboratory, Accelerator and Fusion Research Division, 1 Cyclotron Road, Mailstop 71-259, Berkeley, CA 94720.

33. Thomas E. Shannon, University of Tennessee, Mechanical and Aerospace Engineering and Engineering Science Department, 414 Dougherty Engineering Bldg., Knoxville, TN 37996.

34. Alvin Tollestrup, Fermilab, P.O. Box 500, PPD-EPP Experimental Physics Projects, Mail Station 221, WH 13E, Batavia, IL 6051 O-0500.

35. P. K. Williams, High Energy Physics Division, 19901 Germantown Road, SC-22, Room G-447, Germantown, MD.

36. Michael Witherell, Fermilab, P.O. Box 500, DO-Directorate, Mail Station 105, WE 2E, Batavia, IL $60510-0500$.

37. Bernhard Zeitnitz, Forschungszentrum Karlsruhe GmbH, Institut fur Kemphysik I, postfach 3640, D76021, Karlsruhe, Germany.

38. Christian Zeitnitz, Institut fuer Physik, Universitaet 55099, Mainz, Germany.

39. Michael Zisman, Lawrence Berkeley National Laboratory, Accelerator and Fusion Research Division, 1 Cyclotron Road, Mailstop 71-259, Berkeley, CA 94720.

40. Office of Scientific and Technical Information, P.O. Box 62, Oak Ridge, TN 37831. 
